\title{
Literacy in a Dying Language: The Case of Kuot, New Ireland, Papua New Guinea
}

\author{
Eva Lindström \\ Department of Linguistics, Stockholm University, Sweden
}

\begin{abstract}
Kuot is a language in a critical situation. Most adults of lower middle age and older are full speakers but children are not learning it. In other words, it will become extinct in a few decades if nothing is done; but it is not too late if the community decides to turn it around, and do so fast. Thus far, the community has shown little interest. Into this situation, vernacular elementary education was introduced. While the community expects this to work for language survival, the aim of the education policy is the eventual transfer of literacy skills to English. This paper describes the tensions between these conflicting goals, and the various components that make up the specific situation of Kuot, including vernacular literacy, orthographic considerations arising from the language's precarious situation, and the eventual extension of the internet era to Melanesia.
\end{abstract}

Keywords: vernacular literacy, orthography, education, Papua New Guinea, Papuan languages, language death

\section{Vernacular Education in Papua New Guinea}

Papua New Guinea is the only country in the world to recognise over 800 languages as official languages of the education system. (Peter M. Baki, Secretary for Education, in PNG Department of Education, 2003a: iv)

Students learn best when they use their own language in ways that are meaningful, practical and relevant to them. This means that students in Elementary will learn first in their own languages, languages they already speak. (PNG Department of Education, 2003b: 13)

Since 1993, Papua New Guinea (PNG) has gradually implemented an ambitious education reform in which respect for the diverse cultural values of PNG is stressed. Teaching in all subjects, especially in the first years of schooling, is to start from the children's pre-existing knowledge and skills in very practical ways, and to centre on community activities and values, whenever possible. Oral styles and genres are given as much space as written ones, and the relevance of education for village life as well as the labour market is considered. The policy therefore clearly reflects a local literacy focus as well as a national literacy focus (cf. Liddicoat, 2004). Prior to the implementation of the reform, English was the medium of instruction at all levels (probably together with Tok Pisin, although its use was officially discouraged) from the time of independence in 1975. The school system was modelled on the Australian one and did not have very much relevance for a newly independent nation largely made up of smallholders who are only peripherally involved in the monetary economy. Since independence, 
however, support for an education system based on local conditions and carried out in vernacular languages has grown, and today children are taught in their first languages for three years (Elementary Prep, 1 and 2), and are gradually introduced to English from the second half of the third year (Elementary 2), until English is the only language of instruction from Grade $6 .{ }^{1}$

The fundamental idea behind the reform is that children be taught in their first language until they have basic literacy and numeracy. The elevation of the vernaculars to languages of instruction is welcome. English is considered a difficult language for many people in the Pacific, as it has a very different structure in both its lexicon and its grammar from local languages. It also has a relatively opaque relation between sounds and letters, making it suboptimal for the purposes of introducing the principles of reading and writing. It is, therefore, more logical for learners to be taught English before it is used as a medium of teaching. Although the new curriculum is grounded in community life, the purpose of vernacular literacy is transitional, providing a more efficient route towards the ultimate goal of literacy in English. There appear to be no efforts being undertaken to encourage vernacular literatures or other activities that might help to make the rationale of vernacular literacy clearer. If the goal had been sustainable vernacular literacy, considerable additional requirements would have to be met. Carrington (1997), for example, notes that '[a]mong the principal considerations would be the absolute necessity for a community to perceive literacy in its vernacular as valuable' (p. 85), and according to Crowley $(2000,379)$, '[l]iteracy must, then, become incorporated into people's cultures in order to be successful. This means implicitly that while literacy has been introduced from outside, successful literacy becomes indigenised'.

PNG with a population of only 5 million people has over 800 languages and 435 of these are already in classroom use (Josephs, 1999; Litteral, 2004). Making so many languages mediums of instruction is a daunting prospect. Most of the languages have no traditions of writing, which means that there are no written genres to use in education, and few natural occasions for using reading and writing skills in the vernaculars. It also means that for many of the languages the first obstacle is developing orthographies and coining vernacular expressions for the novel concepts needed even in elementary education and the production of school materials such as readers in all these languages (Liddicoat, 2005). These issues will be discussed in more detail below. Even when all the necessary corpus planning has been achieved, it is not easy to find and educate teachers for languages whose speakers number only in the hundreds (and often several teachers per language are needed as villages may be dispersed across large areas).

\section{The Language Situation in the Kuot-speaking Region}

\section{Kuot}

Kuot is a non-Austronesian isolate language with about 1500 speakers, spoken in New Ireland Province (Lindström, 2002, in preparation) ${ }^{2}$. Kuot speakers reside in around 10 villages along both coasts of New Ireland (see Figure 1), living by a combination of swidden agriculture, fishing, hunting, and cash cropping (mainly copra, cocoa and vanilla). All of the languages in the province, with 


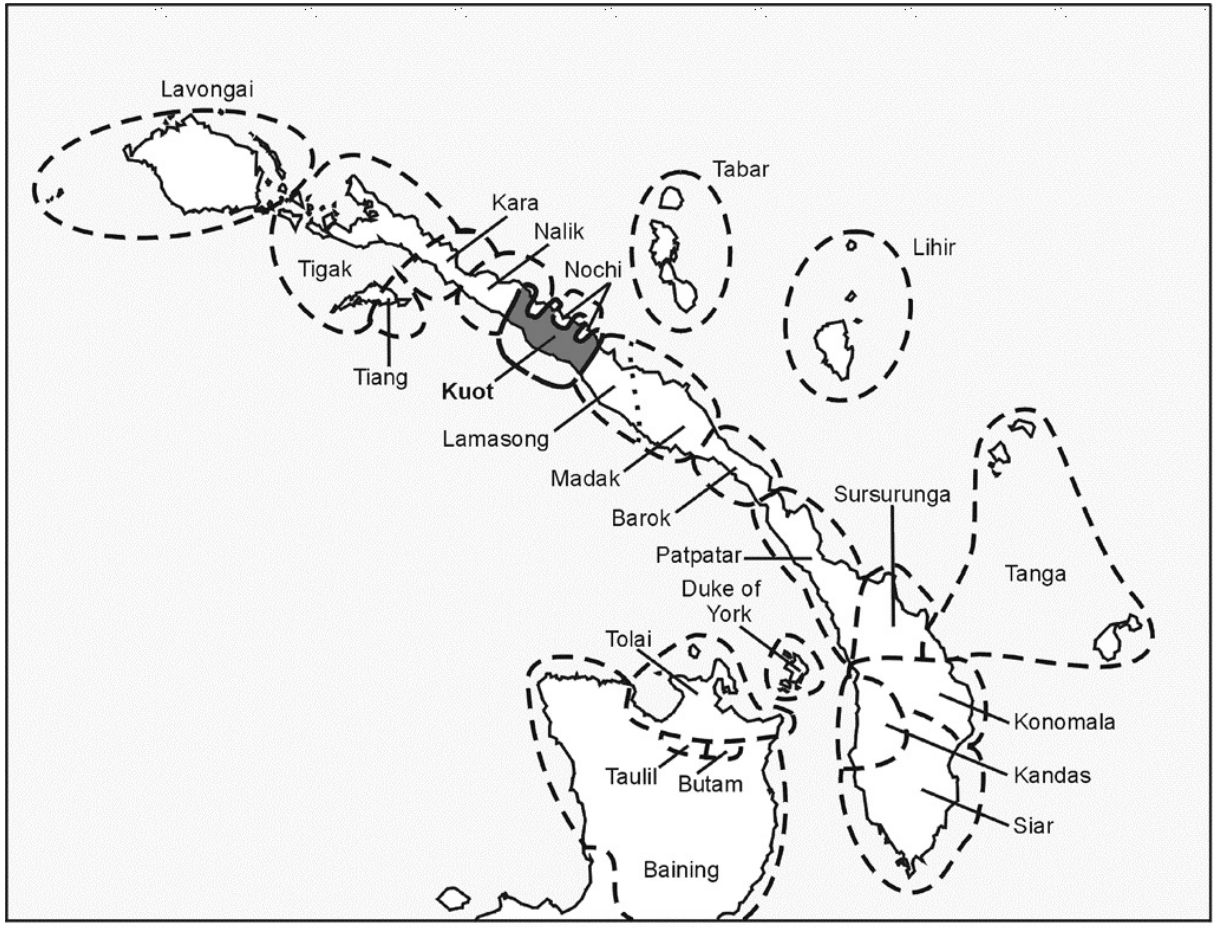

Figure 1 New Ireland language map (with part of New Britain). The shaded area shows the location of Kuot

the exception of Kuot, belong to the Oceanic branch of the large Austronesian language family, and Kuot is generally considered enormously difficult by its neighbours, because it has very different and quite complex morphological structures and is richer in lexical distinctions in some areas. For this reason, Kuot is something of a 'secret language'; in fact the possibility of speaking about somebody who is present often motivates even those who normally never use the language to do so.

All speakers of Kuot are fluent in Tok Pisin and often understand, and sometimes speak, one or more neighbouring languages. Their neighbours, by contrast, sometimes only understand Kuot and rarely speak beyond a few phrases ('good morning, give me a betel nut'). Church services are conducted in Tok Pisin (partly because the pastors are often non-Kuots), although a hymn book with translated United Church hymns is sometimes used. The Monday morning village meetings - a weekly event in all PNG villages - also take place in Tok Pisin.

Dialectal variation in Kuot is small. For historic reasons, villages on opposite sides of the islands speak similarly, with dialectal differences occurring as one moves along the coast. There are no sharp dialect boundaries; rather, sets of features are anchored at either end of the area and extend variously through the territory. The differences are mainly lexical, with a few constructions and small 
phonological and morphological items having a similar distribution. Mutual intelligibility is not a problem.

Most damning for the future of Kuot is the fact that the children's play language is Tok Pisin. Adults of about 35 years of age and older are fluent in Kuot, and played in Kuot when they were children; people of intermediate ages have varying competence depending on their particular personal history. Tok Pisin is used with children even in families where both parents are full Kuot speakers, and it has become the first (and only) language of the majority of Kuot children, starting with the generation now aged approximately 18 . Children are often passive bilinguals and understand Kuot reasonably well but for the most part are not able to speak it.

\section{Tok Pisin and the decline of vernaculars}

Many languages of PNG, like Kuot, are threatened today. Communities are small and mobility has increased steadily ever since the first 'blackbirders' arrived in the 19th century to find contract labour for faraway plantations. The workers brought back an English-lexified pidgin known in PNG as Tok Pisin, which they had used to communicate with foremen and workers from other places. The knowledge and use of Tok Pisin spread and it became a general lingua franca in large parts of PNG. Within PNG too, plantation workers were shipped between regions, and some would stay on after the end of their contracts, often marrying locally. They might learn the language of their new home community, but often the means of communication would remain Tok Pisin. Despite the increased mobility, however, many people still spend most of their lives within a few kilometres of where they grew up, some never leaving their province.

Today, Tok Pisin has come to be used in many situations in village life, often because there is someone present from outside, whether the next-door language or a different province. The widespread knowledge of Tok Pisin in many areas of PNG means that there is no longer a need for multilingualism in order to speak with members of neighbouring linguistic communities. Moreover, the intake areas of schools frequently include more than one language area, and very often the children will communicate with each other in Tok Pisin. In urban areas, children of mixed marriages have been growing up with Tok Pisin as their only language for a few decades now and Tok Pisin has become a creole, developing to cover the whole range of meanings and functions of a fully fledged language. Today, Tok Pisin is also becoming the first language of children in many rural communities, gaining on the vernaculars even in the home.

\section{Kuot, Tok Pisin, and speaker attitudes}

In the main, Kuot speakers do not seem to be emotionally attached to the Kuot language. If you casually remark that 'I reckon this language is about to die', most people will just reply 'it looks that way, doesn't it'. Some express a little sadness about this fact, but there is no great concern. In New Ireland generally, language seems to have little identificational import. Languages, and the groups of people defined by them, did not even have names until the 1950s when the Australian administration introduced language and group names. Group identification was (and is?) associated mainly with the units of village and clan (where 
a clan often has members in more than one linguistic unit, although it will be associated with a particular location, which will be part of a single language area).

It is possible that attitudes to Kuot are influenced by an implicit association of the language with pre-Christian times and practices. Many people take a very negative view of the recent heathen past and it is quite possible that their indifference to the future of their language stems from an association of the language with the lives of their ancestors. Christian missionaries became active in New Ireland in the 1870s and today the dominant religion is Christianity. Many traditional ceremonies are no longer performed, which means that oratory skills have no arena of use and that songs particular to those occasions are also being lost. The fact that Kuot villages no longer have men's houses has removed an important context for story telling.

For Kuot speakers, Tok Pisin does not seem to be associated with the sorts of language attitudes found elsewhere in PNG, in particular attitudes associated with progress, modernity, the independent state of PNG, and other similar positive values. Kulick (1992), who did find such associations in the village of Gapun in another part of PNG, notes that '[a]lways, the shift away from the vernacular language begins generations before the first monolingual speaker of the new language is produced by the community' (p. 248). It may, therefore, be that Tok Pisin did carry urbane connotations for Kuot speakers at an earlier time. However, it must be noted that the people who would have held such views did speak Kuot to their children, and that it is the present generation, for whom no such connotations have been established, who are giving it up. ${ }^{3}$

A further factor in the decline of Kuot is the poor understanding of the mechanisms of language transmission among Kuot speakers, which they appear to share with most of humanity. The need for active contexts of use and the fact that children must grow up speaking a language for it to survive are not widely recognised. In the words of Fishman:

Ultimately, nothing is as crucial for basic RLS [Reversing Language Shift] success as intergenerational mother-tongue transmission. Gemeinschaft (the intimate community whose members are related to one another via bonds of kinship, affection and communality of interest and purpose) is the real secret weapon of RLS. (Fishman, 2001: 458-9).

Rather than seeing language maintenance as active language use, the community's understanding of the situation is reflected in utterances such as 'ah but now you are writing our language down in that book [so it will be preserved]' (speaking of my linguistic reference grammar) and 'ah but now the kids are being taught it in school'. ${ }^{4}$

There are some exceptions to such attitudes. In Okoiok, a small settlement of around six families near Bimun, a man of lower middle age has decided that the language must live and that children must speak it. The means of achieving this goal is to chase the children with a cane if they speak Tok Pisin. This may not give them the best connotations for Kuot, but is successful insofar that there are small children in the village who do not know Tok Pisin. As soon as they are five or six years of age, however, these children go to Bimun to play, and Tok Pisin takes over. Children a little older in that settlement do speak Kuot but with massive 
proportions of Tok Pisin loans. This in itself would not necessarily be problematic, for as long as the children have the morphological structure of the language, they could always replace lexical items if they wished for a 'purer' language. However, the structure of the Tok Pisin lexicon is much less fine-grained than that of Kuot, and these children appear not to be learning many of the lexical distinctions of their language. For example, Kuot has more than 15 verb stems corresponding to 'break' and related meanings in English, depending on what is broken and how, and these are all subsumed under a single word bruk/ brukim in Tok Pisin. Moreover, all loan verbs go into a single class, and the large-scale replacement of indigenous verb stems with Tok Pisin stems means that the morphological patterns of smaller classes appear to be inadequately learnt. This all means that it would not be a matter of simply swapping Tok Pisin stems for Kuot stems, but a matter of acquiring numerous lexical distinctions as well as morphological patterns.

Kuot's Oceanic neighbours seem to be less threatened, in spite of the fact that they are virtually identically configured in terms of size, history, culture and livelihood. On the north-east coast, the smallest language of this area, Nochi, is spoken in two villages. These villages are close to Kuot villages, and the Kuot children there speak Nochi and Tok Pisin, not Kuot. the nature and substance of the fine line separating life and death for these languages remains elusive. The only obvious difference is the fact that the Oceanic languages belong to a single language family, which makes it relatively easy to learn one if you know another. Kuot, by contrast is quite different, with obligatory marking of gender, irregular but obligatory marking of plural on nouns, different inflection patterns for different classes of verbs and adjectives, agreement marking of objects on transtive verbs, and various other features that are typically not present in the neighbouring languages. In the absence of any generally recognised criteria, I hesitate to suggest that Kuot is objectively more difficult for an adult to learn. But it is at least conceivable that Kuot speakers have been used to adapting to neighbours' languages for centuries, just a little bit more than vice versa, so that the tendency for a Kuot speaker to default to Kuot is that bit weaker than for a speaker of Nochi, Madak or Nalik to default to their languages, and that this weaker tendency is enough to tip the tables.

As regards Tok Pisin vis à vis English, quite a number of young and middle-aged Kuot people are quite confident in English, but it is my impression that for most, speaking English is like wearing a special coat - you put it on, as it were. English is the language of school, and the language for speaking with occasional whites. Speaking Tok Pisin, on the other hand, involves no alternations whatsoever to the normal self. Tok Pisin is the language of equals.

\section{Literacy levels}

The adult (that is aged 15 and over) literacy rate in PNG was 64.6\% in 2002, according to the Human Development Report (United Nations Development Programme, 2004a). The literacy rate is defined as follows: 'The percentage of people [ ... ] who can, with understanding, both read and write a short, simple statement related to their everyday life'. (United Nations Development Programme, 2004b). In the census figures for 2000 , the literacy rate of $56.2 \%$ is available broken down by language, showing that literacy in Tok Pisin leads at 
$45.2 \%$, followed closely by vernacular languages (41.7\%) and English (40.4\%) (National Statistical Office of Papua New Guinea, 2003).

The national literacy figures are low, but it is my impression that actual New Ireland figures may be much higher. Even the generation who hardly attended school because of the war have basic reading and writing skills: the old men and at least some of the old women will read from the Bible in church, and some have worked on the Bible translation committee led by the SIL team Kyung-Ja and Chul-Hwa Chung. Assuming that every member of the post-war generations is literate is probably exaggerated given that daily life in the village does not often involve the display of reading and writing skills, but illiteracy does not appear to have been an issue in appointing office-keepers in church or tally keepers at games at big holidays, and so forth. The exercise books with notes from Bible study classes that people sometimes take to church attest to quite fluent writing at least among people aged around 45 and below.

\section{Contexts of literacy}

The relatively high level of literacy in the Kuot community does not mean that it is a literate culture. On the whole, written information is distrusted and people find it easier to relate to spoken information, because they know something of the speaker. The only printed material in most homes is portions of the Bible (in English, Tok Pisin or, of late, the New Testament in Kuot), perhaps some election campaign posters (mostly in Tok Pisin), and the family members' health books (in English); there may be some school books (typically in English) and a torn copy of the Air Niugini in-flight magazine (also in English). There is little care taken to preserve books or other written materials, or to keep records. There are few uses for writing in a PNG village setting. The storekeeper might post a sign saying 'No credit whatsoever!' (in Tok Pisin) and people occasionally make shopping lists when going to town. If you want to send someone a message you tell someone going that way to tell them; as there is no mail delivery in rural areas, you would have to send someone anyway. There are also few occasions for reading in the way Westerners read: alone with a book. Solitude is not culturally encouraged - for the most part only mad people and sorcerers would seek it. And at least in the Kuot area (coastal and hot), life is lived outdoors, near the house or in the open-walled cooking house, in the constant company of anyone else who is about. It would take quite a lot of determination to find the social and physical space to read.

The church is the most important context for adult literacy, while for children school is the most salient context. Since the establishment of vernacular elementary education, children in or near villages that have elementary schools attend them. After second grade they go to community primary school, which has a larger intake area; in the case of Bimun, the nearest school is in the next language area. For those who continue past Grade 8, there are presently five high schools in New Ireland, offering Grades 9-10, and one offering Grades 11-12. Grade 10 or 12 leavers sometimes find employment in office work or can go on to higher education at the national level.

Although Tok Pisin is discouraged at all levels of education, locally, ${ }^{5}$ it is a natural means of communication between children of different languages (and these days also among children of the Kuot community). Somehow, some writ- 
ing conventions for Tok Pisin have developed, such as writing words of reduplicated form (e.g. kaikai 'food', liklik 'little') in 'squared simplex form' ( $\left.k a i^{2}, l i{ }^{2}\right)$. I suspect this has evolved primarily in letter-writing between school friends in high school when separated in holidays or after leaving school.

The only printed materials in Kuot are the New Testament (Chung \& Chung, 2001) with parallel Kuot and Tok Pisin text, two earlier Gospils, and a hymn book (Kuot Hymnbook Committee, 1994) with hymns translated from Kuanua (the language of the Tolai in New Britain, formerly a mission language of the Methodist church), all produced by the SIL team Chul-Hwa and Kyung-Ja Chung and translation teams led by them. They also produced some literacy materials for the informal vernacular pre-school that preceded the education reform. It does not appear that any materials written in Kuot were initiated entirely locally, although some may exist; there are some letters, and some stories written down by elders for the use in the vernacular elementary school.

An entirely new context for interacting through text may appear if UNESCO's vision of 'Information and Communication Technologies for every Pacific Islander' (UNESCO, 2002a, 2002b) is realised. This still seems some way into the future for a place like Bimun village, given that the nearest steady power supply and telephone line are more than 100 kilometres away in the provincial capital of Kavieng. ${ }^{6}$ If and when the internet does become generally accessible, it is clear that literacy has to involve more than encoding and decoding language as text. With the masses of information on the internet, users need the skills to locate information and to evaluate its accuracy and relevance. To participate actively in the world as mediated by the internet, they further need to know how to communicate via e-mail, and preferably also how to create web sites to express themselves, their business ventures for instance in the lines of tourism or agricultural produce, cultural activities or any other of the many topics to which the internet is suited. With computers in mind, it becomes apparent that literacy is a complex phenomenon. Liddicoat (2004), speaking of a regional literacy strategy in Queensland, Australia, expresses this more advanced notion of a literate person eloquently:

... the strategy constructs the literate subject as a person who is a sophisticated user of texts who engages with literate practice as a decoder of text, as a maker of meanings, as a purposeful user of information and as a text analyst bringing critical thinking skills to literate work. (Liddicoat, 2004:9)

While there is a big technological threshold to be overcome to access a computer-based medium, requiring what is sometimes known as computer literacy or technological literacy, the internet provides a platform for vernacular language use. When it comes to using an unfamiliar written form of a vernacular language, personal communication by e-mail is particularly suitable, as it is an informal and unsupervised form of communication and expression.

\section{Language Planning and Vernacular Education in Kuot}

\section{Kuot in schooling}

Most Kuot children speak Tok Pisin as their first language, rather than Kuot and the National Curriculum Statement is quite explicit about the possibility of using Tok Pisin as the language of elementary education: 
This language [the students' own language] may be one of the 800 plus vernacular languages or a lingua franca (Motu, Tok Pisin, English). They will use the language they most commonly use to speak to communicate ideas to others, to learn to read and to listen to other people's ideas in all areas of the curriculum. (Department of Education, PNG, 2003b: 17)

Several schools in other parts of the country have decided on Tok Pisin as the language of instruction (Siegal, 1992). Yet communities in the Kuot-speaking area have chosen Kuot to be the language of instruction in the elementary schools. This is not entirely surprising, because the policies regarding language in education are expressed in such a way that there is a clear expectation that the norm will be for the vernaculars to be used. The stage preceding the present education reform was known locally as tok ples priskul in Tok Pisin, i.e. vernacular preschool. These preschools were established through the 1980s in various areas by provincial governments, in cooperation with the Summer Institute of Linguistics (SIL) (Litteral, 2004). The term tok ples from (English 'talk' and 'place, village') can mean 'language' generally but is most often interpreted as 'vernacular language' and the term tok ples skul is still used in the context of first language programmes. It appears that the local people interpret tok ples skul as a school where the vernacular is used, and that language maintenance is part of the purpose of such schools. This means that the community's conception of the purpose of education in the vernacular is that it is a means of language maintenance. The purpose inherent in the policy, however, is as a means of achieving literacy as such, via L1, with the ultimate goal of literacy in English. These conflicting expectations represent a challenge for the success of the programme, perhaps especially in terms of the success of literacy development.

The result of using Kuot as a language of instruction is that children are still taught in a language they do not speak, but now it is Kuot rather than English. Since many of them are passive bilinguals in Kuot and hear it often, and since the semantic organisation of the Kuot lexicon ties in with their everyday life (and has many overlaps with Tok Pisin), it is probably less problematic for learning that the use of English. However, although vernacular education may have some marginal effect on language survival, it is evident that Tok Pisin would be the obvious choice from the point of view of content learning. Tok Pisin is the L1 of these children, and, in the words of the policy makers, is 'the language they most commonly use to speak to communicate ideas to other', which lets them 'use their own language in ways that are meaningful, practical and relevant to them'. The government aims for the policy could, therefore, be fulfilled if Tok Pisin were used, but it would be contrary to community expectations for the programme.

The community decides on the language of instruction, selects a teacher and supports him or her through training. They select a plot for the vernacular school building and they build and maintain it. The school house if often built from bush materials and located in the village or near the church (if the church is separate from the village), although children from several villages may attend. The community further contributes to the school by writing texts and coming into school to tell the children stories, talking of traditional practices, or showing skills such as carving mini canoes and weaving baskets. 
The Kuot area faces a number of implementation problems, which also affect the nature of the programmes being offered. There are only two elementary schools operating on the west coast and one on the east coast, for the 10 or so villages in the Kuot-speaking area, which covers more than 30 kilometres of coastline, and not all children can attend for practical reasons. The teacher in the east coast school is not a fluent Kuot speaker and does most of his teaching in Tok Pisin limiting the impact of Kuot and the potential for language maintenance. On the west coast, the situation is slightly better. The teacher in Bimun Elementary School - Delvin Molongas - is very positive about the effects of vernacular education, and says it 'opens the children's minds' and that children who have come through elementary school invariably perform well when they go to primary school. According to Delvin, non-speaker children start speaking within weeks of joint the classes.

In the middle of 2004, Delvin had 21 children in her school: six in Prep, six in Elementary 1, and seven in Elementary 2. There is only one small classroom, and the different grade groups sit separately on the sand-covered floor and are given separate tasks to perform during the day from 8.00 am to midday. All the children participate together in some tasks. The use of Tok Pisin is banned, Kuot being enforced even during breaks. Activities seem to follow the official curriculum and its intentions quite well, with emphasis on oral skills in addition to reading and writing, and methods based on local conditions and practices as far as practicable. Some examples of activities are:

- talking in small groups on a set topic, with a spokesperson to report the discussion to the class;

- telling and/or acting out stories prompted by pictures drawn from a deck of picture cards;

- drawing own stories, with writing depending on the grade level;

- beginning maths by counting leaves, stones, etc;

- drama;

- singing songs (often translated from English);

- playing games (chasing/catching games, games of throwing stones into tins, etc.).

The materials used - whether printed or stencilled - have a range of different origins. Much material was provided by AusAID, the Australian government's overseas aid programme, and these materials are typically provided in Tok Pisin and / or English and translated into the vernaculars by the teachers during their training. Among AusAID materials in Bimun Elementary school are six big books, with illustrated stories, and maths books. There are also literacy materials for an earlier vernacular school project by the Chungs, with illustrations by local people, as well as stories provided by community members. There is also a cassette tape with stories of different types and lengths, which I collected during field work.

On the whole, these activities accord well with the intentions and objectives expressed in Elementary Syllabus, under the heading 'Teaching and Learning':

Elementary education is based on the children's own languages and cultures. The classes should have an integrated curriculum which is organ- 
ised under the following subjects - Language, Cultural Mathematics and Culture and Community. [...]

Teachers should be encouraged to develop activities using a range of teaching methods, materials and other support resources that are relevant and appropriate to students' cultural and language needs. Students should work as individuals and in groups.

Some students learn best through such activities as reading on their own, working in small groups, talking with peers, observing, drawing pictures, writing stories with others and finding information for themselves. Most students use a combination of these. (Department of Education, PNG, 2003a: 6)

\section{Effects of Kuot in school}

In the few years since the introduction of elementary education in Kuot, the ability of children who attend it to express themselves in Kuot has increased although it began from a very low base and remains limited. These children begin school at age five or six, and by then have missed out on several formative years in terms of language acquisition. After a few years of speaking it for a few hours a day in the elementary school programme, they still have very low proficiency in all areas of language (vocabulary, morphology, grammar, range of constructions). For example, in 1998, the Kuot competence of the children of my host family consisted of a few set phrases and about 10 or 15 nouns. ${ }^{8}$ They would play a game, asking each other how to say 'dog', 'chicken', etc. in Kuot. When asked what the word for many dogs or many chickens would be, they had no idea. In 2004, they occasionally still played a game with the language, consisting in speaking it to each other - at one point a 14-year-old and his cousin decided to speak only Kuot for two days, and his younger siblings (aged about 9 and 10) joined in for some of the time. They were able to produce very limited sentences and these were full of mistakes, primarily in terms of inflectional categories, and number and gender agreement, but also in the choice of words and actual forms of stems. The response of adults to the faulty language produced by the children is not particularly supportive ('you nitwit, that's not how it's said, you don't know how to speak this language'). As an illustration to the ongoing decline of the language, the youngest child in the family, aged five and not yet in Prep, does not even have passive competence; she could not understand her older siblings and would not participate in the language game.

It would appear that learning to read and write through the medium of Kuot is not going to make a difference to the long-term survival of the language. Kuot is not a language that the children feel at ease speaking, and it would take much more to achieve fluency. The school's impact might be greater if the community followed up by using Kuot with the children outside school, but since that is not the case, speaking Kuot remains a game-like activity which children engage in at particular times when instructed to do so or when the fancy takes them. Thus, language maintenance expectations of the community are not really being fulfilled - largely because of the low level of active maintenance support from community members themselves outside school. For Kuot children, school is the only domain for using Kuot at all, and only for the three years from Prep to Elementary 2 and there remain few authentic reasons to use either written or 
spoken Kuot outside the classroom. It has often been noted that a language will not survive if it is only used in school, e.g. by Fishman:

... languages are not their own rewards. If they remain functionally locked away in the schools, they may be learned (youngsters have an amazing ability and capacity to learn 'useless' matters which they never need again, once their schooling is over), but they will not accomplish the wonderful goals of communication with neighbours far and near [ ...]- and much, much less will they accomplish RLS [Reversing Language Shift] - unless they are linked to 'real life'.... (Fishman, 2001: 471)

A school programme cannot, therefore, be the sole vehicle for language maintenance and is of limited use in a context of language death unless supported by language use in other domains. While the community's maintenance goals are not being met by the programme, neither are the literacy goals of the education policy, as literacy is developed in a language in which the children are at best passive bilinguals (or extremely basic-level active bilinguals), and the children do not develop very good levels of proficiency in either oral or literate forms of Kuot.

\section{Corpus planning for Kuot}

In developing a vernacular language programme in a non-literate culture, there is a substantial amount of preparatory work which is needed and there are many considerations to be taken into account when developing a written form of a language, and putting it to use in new areas. Liddicoat (2005) discusses the many aspects of corpus planning, i.e. the actions of language planners to fix a standard for the written form of a language, in the process of extending the uses of a language into new domains. Corpus planning is divided into two processes: codification, developing a standard form of the language, including a system for writing the language ('graphisation'), a standardised grammatical ('grammatication'), and a standardised vocabulary and terminology ('lexication'); and elaboration, the development of linguistic resources for communicating new topic areas and genres, such as school subjects, official documents or literary genres.

It is useful to split up the creation of a written language into its component parts, each to be considered carefully for the potential consequences of every decision that goes into each part. There are many reports of negative unintended consequences, perhaps particularly in unwittingly creating a status variety (the standard) and thereby also less prestigious varieties (those not selected for the standard language) (e.g. Liddicoat, 2000). In other cases, an unwieldy orthography, or one based on a flawed analysis of the language, has meant low acceptance from speakers (Rehg, 2004). In addition, standardisation is not seen as top priority by all. Charpentier (1997: 233) argues that concepts of standardisation may not be culturally relevant: ' . . perhaps norms are in fact less important than we Westerners, conditioned by our very standardised written languages, might assume. After all, our own standardisation is only a product of the eighteenth and nineteenth centuries; [ ... ] for the vernaculars each scribe and each publishing house had their own conventions in Europe until printing had been established for at least two centuries.' (p. 233) He notes that the Vanuatu pidgin 
speakers of whom he writes are very tolerant of orthographic variation, creatively spelling novel terms as they have perceived them over the radio. The audience appeared not to be at all disturbed by the variation caused by the influence of French or English schooling, respectively, on the writing. Rehg (2004), as the result of long experience of literacy efforts in healthy languages of Micronesia, with a particular focus on Pohnpeian, argues that language standards need to evolve over time. He gives the following continuum of evolution:

(1) Illiteracy $\rightarrow$ (2) Preliteracy $\rightarrow$ (3) Laissez-faire Literacy $\rightarrow$ (4)Standard Language

Explaining the stages, he writes:

Stage (2) occurs when a preliminary writing system exists for the language, but is controlled by relatively few speakers and is used for limited purposes, such as signing one's name. Stage (3) arises when many speakers know how to write the language, and they employ writing for a variety of functions, but no widespread agreement exists concerning how words are to be spelled or perhaps even what letters are to be employed. Stage (4) typically emerges when there is widespread literacy, and, perhaps most important, when there is a substantial amount of material being published in the language. Thus, in planning for the development of a standard language, it might be preferable to establish incremental goals, rather than to try to impose a comprehensive set of standards in one fell swoop. (Rehg, 2004: 510)

In terms of writing activity, Kuot is between Rehg's stage (2) and stage (3), however; the Kuot people do not write much (in any language) and so making judgements about the forms of Kuot they use is difficult. On the other hand, Kuot is now a language of instruction in schools, which would imply a higher level of standardisation, such as (4). The introduction of the vernacular education policy therefore appears to bypass stages of 'organic' development of language standards in societies, such as the Kuot community, where literary practices are not an integrated part of daily life.

The obvious difference between Kuot and the languages considered by Rehg is that Kuot is a dying language and in this context, Rehg's argument about standardisation would appear even more to the point:

... promoting mastery of the standard spelling system for these languages should be de-emphasised in favour of encouraging people to produce written materials that serve the needs and aspirations of the community. (Rehg, 2004: 511)

In practical terms, for Kuot, this would mean that there should be a usable orthography that people approve of and accept; i.e. one part of Liddicoat's (2005) graphisation, need and decisions also need to be made for where to make word boundaries and how to treat phonological processes that occur across such boundaries, for the production of school texts. However, this orthography need not be strictly enforced in student texts or in the writing of speakers. If an authentic context for literate practice arises, it would be counterproductive if someone 
who was inspired to write in Kuot was deterred because school children or others said they cannot do it properly. Since most children leaving Grade 2 to go on to Primary school have rather limited proficiency in spoken Kuot, they are not likely to suffer from not being able to write it according to a well-defined set of rules.

The level of standardisation required in initial stages of the development of literate practice, therefore, has to be determined with regard to the particular situation and ecology of each language. Standardisation of orthography (and of other elements of the language) would seem to be more crucial for a language where official and administrative uses are foreseen, and where the vernacular is to be used in education at higher stages than elementary school. Should there be efforts to revitalise Kuot and texts start to be produced in any number, the matter of standardisation can be reconsidered. A non-standardising approach also neatly sidesteps the problem of choosing a standard lexicon and grammar for the written language, for the time being. Both the Chungs and I have worked in the southern part of the Kuot territory, and when I visited villages in the north the inhabitants expressed some concern that they and their variety of the language had been neglected. Leaving the issue open means everyone can use the variety they feel most comfortable with, and since the dialectal differences are not great this will not impede mutual understanding.

There is also the issue of what wider consequences may arise from putting a language into writing at all. This is an area of much disagreement. Mühlhäusler (1996) argues that the introduction of literacy as such into a society has radical consequences: linguistic diversity is lost; thought patterns are changed; society is restructured; and if it is literacy in the vernacular, it heralds language shift to the 'metropolitan language' - dire consequences indeed. Charpentier (1997) is also pessimistic regarding the effects of vernacular literacy: 'It would seem that by being written these languages enter into a competition against the "big" languages with literary traditions' (p. 229). He argues that once speakers move on to literacy in languages like English or French, they will compare their own language to the body of world literature and find their own language (to which he ascribes low prestige across the board) deficient and lacking. In response to these ideas, Crowley (2000) denies that there is a simple, automatic causal correlation between literacy as such and the decline of vernaculars, nor are the changes in society, thinking etc. over the last century attributable to the introduction of literacy alone. He argues that the whole history of white contact, mission activities, (at least partial) monetary economy and so forth are responsible for such developments. He further points out that cultures are not, and have never been, static and discrete entities, and that Pacific Islanders have often enthusiastically embraced novelties and incorporated them into their own cultures, literacy included.

However, the idea of being able to compare Kuot to languages with much larger bodies of written work in many genres, thicker dictionaries and so forth, and finding Kuot inferior in various respects, could be a real problem (cf. Liddicoat, 2000). This may in fact be what has happened in implicit ways, for oral and written varieties alike, as part of why people have gradually started abandoning the language. However, as Crowley (2000) argues, it is impossible to foresee the consequences of introducing or not introducing any particular item into a 
language ecology, and providing added channels of expression could equally well have positive effects.

\section{Developing an Orthography for an Endangered Language}

Developing a functioning orthography is a central part of corpus planning, and this section examines the orthography developed to write Kuot from the (often conflicting) points of view of practicality, phonological fit, and acceptability. Some of the features that compete in orthography design are:

- linguists' interests in an orderly system reflecting the phonology;

- the need for a practical orthography (at least for school);

- acceptability to speakers;

- the media where the orthography will be used;

- transferability to writing systems used for other relevant languages;

- (for Kuot) the precarious situation of the language.

Rehg (2004) makes a number of important points regarding orthographies for small languages, some of which are:

- the single most important consideration in the design of a spelling system is the likelihood of its being accepted;

- if it's not broken, don't fix it;

- a phonemic transcription and an alphabet are not the same thing;

- avoid unfamiliar symbols; when feasible, use digraphs rather than diacritics;

- variability is acceptable, particularly in a 'young' orthography.

The first point is that unless speakers accept the writing system, they will not use it as intended, no matter how beautifully designed. The second point is related, and states that this goes both for new orthographies and reforms to old ones. The third point argues that linguists should not become fixated on phonological analyses, as these are often quite abstract creations and writing systems have different requirements - among them those mentioned in the fourth point, which relates to matters such as readability, writing media, and transfer to other languages present in the region. The last point, on standardisation vs. variability, has been discussed above.

There is an orthography in use for Kuot, developed by the SIL team Chul-Hwa and Kyung-Ja Chung during the 1980s in the context of translating the New Testament and associated materials. The orthography uses the Roman alphabet with what may be called 'standard values' for the sounds corresponding to each letter. From a strictly linguistic point of view the system would appear to have problems in terms of both overspecification and underspecification of sound-symbol relationships. For example, in Kuot the grapheme $\langle\mathrm{v}\rangle{ }^{9}$ is used, although the sound $/ \mathrm{v} /$ is derived from $/ \mathrm{p} /$ by regular processes and both could be written with $\langle\mathrm{p}>$ : a case of overspecification, where the orthography gives more information than is strictly necessary in terms of the phonological analysis. The use of digraphs, such as $<\mathrm{ng}>$ for the velar nasal $/ \mathrm{g} /$ can represent either $/ \mathrm{g} /$ or $/ \mathrm{gg} /$ : an underspecification, since the orthography does not distinguish between speech sounds which are distinct in the language. In Kuot, there is also a phonemic distinction between $/ \mathrm{a} /$ and $/ \mathrm{a} /$, but both are written as $<\mathrm{a}>$; another 
Table 1 Kuot phonemes, allophones and letters

\begin{tabular}{|c|c|c|}
\hline Phoneme & Allophone & Symbol \\
\hline $\mathrm{p}$ & $\beta \sim \mathrm{v}$ & $\mathrm{p}, \mathrm{v}$ \\
\hline $\mathrm{t}$ & $\mathrm{r}$ & $t, r$ \\
\hline k & $\gamma$ & $k, x(g)$ \\
\hline $\mathrm{b}$ & $\mathrm{m}_{\mathrm{b}}$ & $\mathrm{b}$ \\
\hline d & $\mathrm{n}_{\mathrm{d}}$ & d \\
\hline g & gg & g \\
\hline $\mathrm{m}$ & & $\mathrm{m}$ \\
\hline $\mathrm{n}$ & & $\mathrm{n}$ \\
\hline y & & ng \\
\hline $\mathrm{f}$ & & $\mathrm{f}$ \\
\hline $\mathrm{s}$ & & $\mathrm{s}$ \\
\hline 1 & $\mathrm{n}$ & $1, \mathrm{n}$ \\
\hline $\mathrm{r}$ & & $\mathrm{r}$ \\
\hline $\mathrm{i}$ & & $\mathrm{i}$ \\
\hline e & & e \\
\hline a & & a \\
\hline ə & & $\mathrm{a}$ \\
\hline $\mathrm{o}$ & & $\mathrm{o}$ \\
\hline $\mathrm{u}$ & & $\mathrm{u}$ \\
\hline
\end{tabular}

case of underspecification. Nonetheless, the orthography works quite well and is accepted by speakers, except in one respect, the treatment of an allophone of $/ \mathrm{k} /$, which will be discussed below.

In principle then, following Rehg's (2004) recommendations, the best solution would be to leave the Kuot orthography as is, except for amending the point where speakers are dissatisfied. Overspecification would not appear to be a problem if the system captures a useful distinction for users, and speakers of many languages tolerate underspecification. Speakers know their language and can fill in the missing information in the written form from their knowledge of the spoken form. However, Kuot is not the healthy language that Rehg has in mind in his discussion. In this perspective, underspecification becomes a problem, because it means that a pronunciation may not be retrievable if the language is being revived, as the user may not be a full speaker. It is necessary to find a compromise between a user-friendly orthography and one that avoids underspecification. It will be useful to look at the phonemes, allophones, and the characters used to write Kuot, given in Table 1, before resuming the discussion. Most require no explanation, and those that do will be discussed below.

There are a number of tensions between the phonemic system and the orthography, if one keeps in mind the discussion so far.

The voiceless stops lenite into voiced fricatives $(/ v \sim \hat{a}, r, \gamma /)$ when they appear between vowels, including across word boundaries. It would be possi- 
ble to write only $<\mathrm{p}, \mathrm{t}, \mathrm{k}>$ but people are used to representing the speech sounds $/ \mathrm{v}, \mathrm{r} /$ with the symbols $\langle\mathrm{v}, \mathrm{r}\rangle$. Moreover, $/ \mathrm{r} /$ is a phoneme in its own right, as well as an allophone of $/ t /$, and speakers would need to be able to undertake a phonological analysis to determine if the sound were an allophone of $/ t /$ or the phoneme $/ \mathrm{r} /$.

The representation of the allophone $/ \gamma /$ has been problematic, and has been a source of speaker dissatisfaction. In Chung's work it is usually rendered $<\mathrm{g}>$, but $<\mathrm{g}>$ also represents the phoneme $/ \mathrm{g} /$, which has quite different properties, and this is a case of underspecification that has not been well received. Insofar as people themselves write Kuot, they have used $<\mathrm{k}>$. Neighbouring languages have equivalent phonological processes, and use $\langle x\rangle$ to represent $/ \gamma /{ }^{10}$ After consultations with teachers in two of the elementary schools and some elders who were members of the (now defunct) Bible translation committee, who all welcomed it, $<x>$ was adopted into Kuot in September 2004. There is a potential problem with the use of $\langle x\rangle$ in tranfer to English, where $\langle x\rangle$ has a different sound value $(/ \mathrm{ks} /)$. However, the Kuot use does adhere to established practice in neighbouring languages, making it a regional orthographic feature.

Another reason to write the lenited sounds with separate symbols is the fact that unlenited / $\mathrm{p}, \mathrm{t}, \mathrm{k} / \mathrm{do}$ sometimes occur between vowels. These are phonologically double (/pp, tt, kk/), which blocks the lenition process, both across word boundaries and sometimes stem-medially. There is no extra length added; the doubling is noticeable only because there is no lenition. To be explicit about the difference between lenited and unlenited, it would be possible either to write $<$ lukkuan $>$ (pronounced /lukuan/) 'village' and <lukuan> (pronounced /luruan/) 'house', or <lukuan> 'village' and <luxuan> 'house'. Since doubling the consonant in the spelling gives an erroneous impression of length, and since there is already a tendency to write the lenited versions using different graphemes from the unlenited versions, and because using $\langle x\rangle$ (etc.) ties in with regional practice, the use of a separate grapheme here is quite satisfactory.

Whether lenition across word boundaries should be indicated in writing is a matter that has not yet been resolved. On the one hand, constancy of form seems desirable, so that a morpheme like pam ('our') is always <pam>; on the other hand, people may feel that indicating lenition everywhere it would occur in speech gives the text more fluency. An illustration of this phenomenon across a word boundary would be the following:

$\begin{array}{lll}\text { aia pam } \quad \text { [aiavam] } & \begin{array}{l}\text { aia-p pam } \\ \text { forfather-PL our }\end{array} \\ \text { forefather our } & \text { 'our forefathers' } \\ \text { 'our forefather' } & \end{array}$

The voiced stops are optionally prenasalised. If the nasal is written, it can lead to the $\langle$ ng $>$ ambiguity discussed above, when the intended phoneme is $\langle$ g $\rangle$, so the simple stop will be consistently used, for example $<$ kudat $>$ for the word 'fence', variously pronounced / kudat kundat/. In the long run, this should be part of the spelling norm for Kuot; but at present it is perhaps more important that people write than that they leave out the nasals in these cases. 
The nasal velar is written with the only digraph in the writing system, $<$ ng $>$. As set out above, there may be confusion with prenasalised /g/, but the digraph has the advantages of using familiar symbols present on a standard keyboard, and corresponding to Tok Pisin and English usage allowing transferability between orthographic systems (cf. Liddicoat, 2005).

The distinction between / $/$ and / $\mathrm{n} /$ is partly phonemic and partly allophonic in Kuot. They contrast in syllable-initial position, but /1/ is disallowed syllable-finally and the contrast is neutralised there. For example, a form like / kin/ 'well, spring' usually becomes / kilip/ in the plural. The linguist might want a consistent representation of the stem (either $<$ kin $>$ or $<$ kil $>$ ) but this is a level of abstraction where, again, the phonological analysis is too abstract to be useful in a writing system. It is not problematic to the speaker, who will simply write what he or she would say. Kuot plural formation has much irregularity, and plural forms will have to be given in full throughout a dictionary, so the variation will be obvious there.

The last item for comment is the central vowel / $/$ /. It too is a sound which is in a partly phonemic and partly allophonic relation with another sound, this time / a /. Both are represented with $<a>$ and speakers seem happy with this. The functional load of the distinction is quite low; that is, there are not very many cases where confusion would arise from using $<a>$ for both.

The orthography as presented here is apparently adequate for the needs of Kuot writers; however, from the point of view of developing a dictionary for a dying language, it would seem unsatisfactory not to represent the pronunciation more fully - if words that are falling out of use are to be accessible, it is essential that the pronunciation is reflected as fully as possible. The solution to this problem involves a number of considerations. The neighbouring Madak language Lavatbura-Lamusong has the same set of vowels and uses $<a>$ for $/ \mathrm{a} /$ and $<$ aa $>$ for / a / . The advantage is that standard characters are used - following Rehg (2004) in using a digraph rather than a diacritic or an unfamiliar character; the drawback is that it gives an erroneous impression of length. Since the distinction seems to have low salience to Kuot speakers, one way would be to use <a> for both in the general orthography but use a diacritic in the dictionary to indicate / / / pronunciation, e.g. < $>>$, so that pronunciation can be retrieved. As speakers are used to considering / $/ \mathrm{/}$ and $/ \mathrm{a} / \mathrm{as}$ equivalent in writing, they would be alphabetised together. The dot would be like stress marks in many dictionaries: a guide to pronunciation but not intended to be reproduced in writing. A problem arises if people should want to make this distinction in their own writing and find no way of reproducing the diacritic on typewriters or computers. A solution would be to use a more common diacritic, such as a circumflex $(<\hat{a}>)$, but these are generally more salient and may run an even greater risk of unintentionally becoming prescriptive simply because they are so noticeable. The dictionary solution, if understood by speakers as normative, would mean introducing a diacritic into the orthography, which Rehg (2004) recommends against. However, given the low level of writing activity in the Kuot-speaking community, and the established practice of using $<a>$ for both sounds, it is unlikely both that a demand for a way of distinguishing them will arise, and that diacritics will be adopted into the general orthography. 


\section{Issues in Developing an Orthography}

This section will examine the Kuot orthography in the light of Rehg's (2004) criteria discussed earlier.

The orthography in use for Kuot may be underspecific in some areas ( $<a>$ for both $/ \mathrm{a} /$ and $/ \mathrm{a} /$ ), and overspecific in others (writing the allophones of $/ \mathrm{p}, \mathrm{t}, \mathrm{k} /$ ), but it is accepted by potential users and by those who do make use of Kuot in its written form (the first of Rehg's points above). Changing an orthography that is accepted may be problematic in itself, no matter how linguistically elegant a suggested alternative may be (Rehg's second point). For Kuot, therefore, it has been decided to keep the practice of writing both / / / and / a / with $<a>$. In the same vein, rather than introducing an unfamiliar symbol $<\mathrm{n}\rangle$, the digraph $\langle\mathrm{ng}\rangle$ is retained, which also helps transfer to other relevant languages. Lenited allophones of $/ \mathrm{p} /$ and $/ \mathrm{t} /$ remain written with $\langle\mathrm{v}\rangle$ and $\langle\mathrm{r}\rangle$, and speakers' dissatisfaction with the allophone of $/ \mathrm{k} /$ has been resolved by the introduction of $\langle\mathrm{x}\rangle$. The use of a symbol for the allophone of $/ \mathrm{k} /$ also allows parallel treatment of the three voiceless stops in representing their allophones with separate characters.

Baker (1997) argues (against Rehg's fourth point above) that modern technology allows for all the diacritics and special characters that we may want for an orthography, so that we need not be limited to typewriter symbols. For Kuot, this could mean using $/ \mathrm{\jmath} /$ and $/ \mathrm{y} /$, moving a little closer to the phonology than with the present orthography. However, Baker's argument seems to overstate the case for the ability of modern technology, which often effectively restricts the choice of characters because of incompatibilities in systems, especially in the use of e-mail. E-mail seems to be particularly important in considering an orthography for vernacular use as, if internet access becomes as widespread, e-mail could be one of the more important areas where speakers of small languages use their languages in writing. It is possible to imagine Bimun people communicating with children in high schools in other parts of the island and with their teachers; with community members working in mines and offices or in clerical education elsewhere in New Ireland or PNG, with sick relatives in hospital; with people in other villages with whom they are organising a funeral, church activities, cultural events and other activities; with the hardware store or copra buyers in town and in other contexts. While not all these communications would take place in Kuot, it would be unfortunate to exclude the language from this arena by designing an orthography that is not reproducible in ASCI. Rehg (2004) notes that e-mail is much used in Micronesia, and that a major reason why letters with diacritics are unsuccessful is that people find them more difficult to type than digraphs. Hence, the issue of transferability applies not only to transfer between the orthographic traditions of different languages, but also to transfer between media - handwriting, typewriter, print, different computer programmes, and between computers in a connected world.

The considerations are relevant for determining a workable and acceptable orthography for writers of the language; however, they may be less useful if language maintenance (and possibly language revival) work is going to rely on written language as a record of the spoken language. The reason to insist on more specification in the Kuot dictionary than in the general orthography is, as indicated, that the language is severely threatened, and the number of fluent speakers will decrease over the coming decades. If there is a movement to revi- 
talise the language, it would be unfortunate to have a dictionary that does not provide full information on pronunciation of words that are being forgotten. For this reason, the dictionary needs to indicate stress, which is unpredictable in Kuot, and somehow identify those instances of $<a>$ which are to be pronounced $/ \mathrm{a} /$. The tentative solution is proposed for the dictionary is an $<\mathrm{a}>$ with a discreet diacritic.

Regarding dictionaries, what has been discussed here is a multidictionary; one that strives to include the entire vocabulary resources of the language. However, it should be emphasised that there is more than a single format for dictionaries. Liddicoat (2005: 13-14) points out that different formats are needed for academic contexts and educational contexts, as well as for different purposes within any particular language community. A multidictionary would have much more information than children in Prep and Elementary school need, and could be quite daunting. In order to support vernacular education, therefore, it would be useful to produce a smaller, preferably illustrated dictionary for school, omitting pronunciation markings, perhaps word class information, and other information that may be considered superfluous or irrelevant for literacy development. Small thematic dictionaries have also been considered, and a preliminary version of an illustrated dictionary showing all the terms for parts of a house has been circulated and met with approval among speakers.

An orthography is necessary for literacy, but there are complex issues surrounding it which impact on orthographic design. The orthography has to be developed before other corpus planning issues can be taken into consideration. The important thing in the context of vernacular education is that there is a spelling system which can be used to develop literacy, that it is adequate for representing the spoken language in written form, that it is acceptable to speakers, and that it is suited to the range of literate contexts in which it may be used. However, where the language is dying, there are competing demands made on orthographies, dictionaries and other materials and multiple solutions may be required for vernacular literacy to achieve the goals of both literacy development and language maintenance.

\section{Conclusions}

The PNG education reform is ambitious and well designed in many respects, stressing the cultural and linguistic diversity of the country and anchoring education in local practices. The idea is for the children to develop their knowledge and social identities from the familiar to the unknown. However, the 'localist' stage in education is transitional: vernacular literacy is a point of departure, not an objective in its own right. Thus, the policy aims to use vernaculars as vehicles for developing literacies which will ultimately be used in other languages, especially English. The policy does not therefore contain measures explicitly designed to maintain languages or cultures, nor is this the aim of the policy. The policy implicitly assumes that the languages being used in vernacular education are the actively transmitted first languages of students. In contexts of language death, however, vernacular language programmes are subject to local understandings of what is meant by vernacular and of the aims and objectives of vernacular language education. In a dying language, where school is 
seen as the arena for halting or reversing a process of language shift, maintenance issues can easily take over from developing literacy skills.

In the case of Kuot, while the policy stresses that the first years of education should be in the children's first language, which in this case is typically Tok Pisin, a local reinterpretation of the concept of education in the vernacular has been as a maintenance policy for the threatened community language Kuot. This changes the context of implementation as well as the possible outcomes: instead of a transition from L1 literacy to L2 literacy, Kuot children develop literacy in a culturally traditional L2, which most of them do not speak, as a precursor to L2 literacy in English, which they also do not speak. The viability of the vernacular language programme is potentially undermined by a mismatch in conceptualisations. An education programme designed as a transitional literacy development programme is unlikely to meet a community's language maintenance objectives, while the acquisition of a culturally traditional language in the school context is unlikely to meet government objectives of accelerated literacy development through L1 and the transfer of literacy skills to other languages. Moreover, schooling is not enough to keep a language alive (Fishman, 2001) - a language needs a whole range of real-world contexts of use where it has relevance to the entire community.

In other words, the maintenance expectations of the Kuot community are not being met, nor is the education policy implemented as intended. In Kuot, vernacular language education is required to do double duty and there are competing aims and objectives for the programme. In developing materials for the vernacular, the range of aims and objectives needs to be considered and this becomes clear in the context of developing an orthography; an orthography for developing literacy and an orthography for recording a language for future generations involve very different assumptions, which in turn may be in conflict with linguists' understandings of appropriate orthography. In the Kuot case, the tensions between aims and objectives have been resolved through the use of multiple solutions: an orthography designed for use in reading and writing with both underspecification and overspecification, and an orthography for recording the language in a dictionary which reduces the underspecification. In addition, for linguists using an orthography for academic communication about the language, a third writing system is needed which reduces overspecification and brings the written representation of the language more closely into line with the phonology itself.

\section{Notes}

1. The new grade structure of the school system is the following: Prep: Grade 0; Elementary: Grades 1-2; Lower Primary: Grades 3-5; Upper Primary: Grades 6-8; Lower Secondary: Grades 9-10; Upper Secondary: Grades 11-12. The old Community Schools which offered Grades 1-6 are being extended to Grade 8, and Provincial High Schools which previously taught Grades 7-10 or 9-10 will provide education until Grade 12 (Kale \& Marimyas, 2003). However, Upper Secondary is available in New Ireland only at Namatanai Secondary School so far.

2. Most of what follows is based on observation during a total of 25 months of linguistic fieldwork, mostly spent in Bimun village on the south-west coast, near the border to the Madak (Lavatbura-Lamusong) language area.

3. Charpentier's (1997) statement that 'in Oceania [...] the omnipresent pidgins have the slums as their cultural reference' (p. 231) is absurd from a New Ireland perspective. 
'Slum' is not a concept and there is no reason to associate a language one uses on a daily basis with any such alien and empirically unattested notion.

4. An example of a language where community attitudes have effected a reversal of language shift is the Wuvulu language in Manus Province in PNG, of a similar size to Kuot. The language was in a difficult position some 25 years ago, with Tok Pisin gradually replacing Wuvulu as the dominant play language of children. Today the language has revived through a change of community attitudes and behaviour, coupled with renewed appreciation of traditional values and practices more generally, alongside Christianity (Kristian Lagercrantz, p.c.).

5. The National Curriculum Statement (PNG Department of Education, 2003b), which covers all grades from Prep to Grade 12, does say that ' [s]tudents are encouraged to use their own languages both in and out of the classroom' (p. 14), but, perhaps because the vernaculars are locally defined as first languages for education purposes, Tok Pisin is not used in school contexts in this area.

6. Various technical possibilities for spreading internet services have been explored (see Zwimpfer, 2003).

7. In the National Curriculum Statement (Department of Education, PNG, 2003b) computing is mentioned for the lower and upper secondary school only, in the Culture and Community learning area (pp. 31,34), among many other topics to be covered within that area. A UNESCO (2002c) report on the development and use of internet infrastructure in Pacific member states identifies a number of obstacles for internet use, including computer and internet access, bandwidth, as well as relevant skills.

8. There are also a number of Kuot plant and fish names and so on which are used in Tok Pisin, as that language does not have great resources in those areas, but children's knowledge of such terms cannot count as Kuot competence, since they have been acquired in a Tok Pisin context.

9. The following conventions will be used throughout this paper: / / indicates a speech sound, whether a phoneme or an allophone; <> indicates a grapheme of the written language.

10. In the International Phonetic Alphabet, $/ x /$ stands for a voiceless velar fricative, while it is here being used for a voiced one $(/ \gamma /)$. Since in these languages, there is no contrasting voiceless velar fricative and $<x>$ has no other uses, this is in fact a very good solution to the problem.

\section{Acknowledgements}

This work, as part of the European Science Foundation EUROCORES Programme OMLL, was supported by funds from Vetenskapsrådet and the EC Sixth Framework Programme under Contract No. ERAS-CT-2003-980409. I want to thank Tony Liddicoat for his comments, and Gunnar Eriksson for reading several drafts and providing lively discussion and many helpful suggestions.

\section{Correspondence}

Any correspondence should be directed to Eva Lindström, Institutionen för lingvistik, Stockholms universitet, SE-106 91 Stockholm, Sweden (evali@ling.su.se).

\section{References}

Baker, P. (1997) Developing ways of writing vernaculars: Problems and solutions in a historical perspective. In A. Tabouret-Keller, R.B. Le Page, P. Gardner-Chloros and G. Varro (eds) Vernacular Literacy: A Re-Evaluation (pp. 93-141). Oxford: Clarendon.

Carrington, D. (1997) Social contexts conducive to the vernacularisation of literacy. In A. Tabouret-Keller, R.B. Le Page, P. Gardner-Chloros and G. Varro (eds) Vernacular Literacy, A Re-evaluation (pp. 82-92). Oxford: Clarendon. 
Charpentier, J-M. (1997) Literacy in a pidgin vernacular. In A. Tabouret-Keller, R.B. Le Page, P. Gardner-Chloros and G. Varro (eds) Vernacular Literacy (pp. 222-45). Oxford: Clarendon.

Chung, C-H. and Chung, K-J. (2001) Bais Ula Mumuru Aime Iesu. Port Moresby: Bible Society of Papua New Guinea.

Crowley, T. (2000) The consequences of vernacular (il)literacy in the Pacific. Current Issues in Language Planning 1 (3), 368-88.

Fishman, J.A. (2001) From theory to practice (and vice versa): Review, reconsideration and reiteration. In J.A. Fishman (ed.) Can Threatened Languages Be Saved? Reversing Language Shift, Revisited: A 21st Century Perspective (pp.451-83). Clevedon: Multilingual Matters

Josephs, J. (1999) Education for all (EFA) assessment: Papua New Guinea Country Report. On WWW at http://www2.unesco.org/wef/countryreports/papua_new_guinea/ contents.htm. Accessed 14.03.05.

Kale, J. and Marimyas, J. (2003) Implementing multilingual education in a country with 860 languages: Challenges for the National Department of Education in Papua New Guinea. Paper given at Language Development, Language Revitalization and Multilingual Education in Minority Communities in Asia, Bangkok, 6-8 November. On WWW at http:// www.sil.org/asia/ldc/parrallel_papers/kale_and_marimyas.pdf. Accessed 10.06.05.

Kulick, D. (1992) Language Shift and Cultural Reproduction: Socialization, Self, and Syncretism in a Papua New Guinean Village. Cambridge: Cambridge University Press.

Kuot Hymn Book Committee (1994) Babam o Punuarap: Sasangip O Ties Onim Kuot: Kuot Hymn Book. New Ireland, Papua New Guinea.

Liddicoat, A.J. (2000) The ecological impact of a dictionary. Current Issues in Language Planning 1 (3), 424-30.

Liddicoat, A.J. (2004) Language planning for literacy: Issues and implications. Current Issues in Language Planning 5 (1), 1-17.

Liddicoat, A.J. (2005) Corpus planning: Syllabus and materials development. In E. Hinkel (ed.) Handbook of Research in Second Language Teaching and Learning (pp. 993-1012). Mahwah, NJ: Lawrence Erlbaum.

Lindström, E. (2002) Topics in the grammar of Kuot - A non-Austronesian language of New Ireland, Papua New Guinea, Unpublished PhD Thesis, Department of Linguistics, Stockholm University.

Lindström, E. (in preparation) A descriptive grammar of Kuot, a non-Austronesian language of New Ireland, Papua New Guinea.

Litteral, R. (2004) Vernacular education in Papua New Guinea. On WWW at http:/ / portal.unesco.org/education/en/file_download.ph p / 177dffa9b9572a29963e844ed0e012faLitteral,+Vernacular+education+in+PNG,+7+May .doc. Accessed 14.03.05.

Mühlhäusler, P. (1996) Linguistic Ecology - Language Change and Linguistic Imperialism in the Pacific Region. London: Routledge.

National Statistical Office of Papua New Guinea (2003) Education statistics from 2000 census. On WWW at http://www.spc.int/prism/country/pg/stats/ Pop_Soc_\%20Stats / Social/Education/literacy.htm. Accessed 14.03.05.

PNG Department of Education (2003a) Language, Elementary Syllabus 2003. On WWW at http: / / www.pngcurriculumreform.ac.pg/text/Curriculum/elem\%20curr / langprelim.pdf. Accessed 14.03.05.

PNG Department of Education (2003b) National Curriculum Statement for Papua New Guinea. On WWW at http://www.pngcurriculumreform.ac.pg/text/Curriculum/ elem\%20curr/langprelim.pdf. Accessed 14.03.05.

Rehg, K. (2004) Linguistics, literacy, and the law of unintended consequences. Oceanic Linguistics 43, 498-518.

Siegel, J. (1992) Teaching initial literacy in a pidgin language: A preliminary evaluation. In J. Siegel (ed.) Pidgins, Creoles and Non-standard Dialects in Education (pp. 53-62). Melbourne: Applied Linguistics Association of Australia.

UNESCO (2002a) Draft Pacific Islands Regional Information and Communication Technologies Policy. On WWW at http://webworld.unesco.org/publications/it/ 
Policy / Pacific\%20 IT\%20Policy\%20Strategies\%20-\%202001\%20CROP\%20meeting.pdf. Accessed 14.03.05.

UNESCO (2002b) Draft Pacific Islands Regional Information and Communication Technologies Strategic Plan. On WWW at http:/ / webworld.unesco.org/publications / it / Policy / Pacific\%20IT\%20Strategy\%20-\%202001\%20CROP\%20meeting.pdf. Accessed 14.03.05.

UNESCO (2002c) Internet infrastructure and e-governance in Pacific islands countries: A survey on the development and use of the internet. On WWW at http:// portal.unesco.org/ci/en/file_download.php/bcc99cd450940e78925b8a2113c751732002 +Internet+Survey+Final.doc. Accessed 22.03.05.

United Nations Development Programme (2004a) Human development report, Papua New Guinea. On WWW at http://hdr.undp.org/statistics/data/cty/cty_f_PNG. html. Accessed 14.03.05.

United Nations Development Programme (2004b) Definitions of statistical terms. On WWW at http://hdr.undp.org/docs/statistics/understanding/definitions.pdf. Accessed 14.03.05

Zwimpfer, L. (2003) ICTs for development: Towards a connected Pacific. On WWW at http://portal.unesco.org/ ci/en/ev.php-URL_ID = 13258andURL_DO = DO_TOPICandURL_SECTION=201.html. Accessed 14.03.05.

\section{The Author}

Eva Lindström is a researcher in the Department of Linguistics at Stockholm University, where she completed a PhD on the grammar of Kuot in 2002. 